\title{
Silymarin seed extract supplementation enhances the growth performance, meat quality, and nutrients digestibility, and reduces gas emission in broilers
}

\author{
Sureshkumar Shanmugam ${ }^{1, a}$, Jae Hong Park ${ }^{1, a}$, Sungbo Cho ${ }^{1, *}$, and In Ho Kim ${ }^{1, *}$
}

\author{
* Corresponding Author: \\ Sungbo Cho \\ Tel: +82-41-550-3652, Fax: +82-41-550-3652, \\ E-mail: blue0555@hotmail.com \\ In Ho Kim \\ Tel: +82-41-550-3652, Fax: +82-41-550-3652, \\ E-mail: inhokim@dankook.ac.kr \\ 1 Department of Animal Resource and \\ Science, Dankook University, Cheonan \\ 31116, Korea \\ ${ }^{a}$ Authors are equally contributed. \\ ORCID \\ Sureshkumar Shanmugam \\ https://orcid.org/0000-0001-5160-323X \\ Jae Hong Park \\ https://orcid.org/0000-0002-2025-0141 \\ Sungbo Cho \\ https://orcid.org/0000-0002-2593-2758 \\ In Ho Kim \\ https://orcid.org/0000-0001-6652-2504
}

Submitted Dec 9, 2021; Revised Jan 7, 2022; Accepted Feb 10, 2022
Objective: A feeding trial was carried out to determine the effect of dietary inclusion of silymarin seed extract on growth performance, nutrient digestibility, excreta microbiota, excreta gas emission, blood profiles, and meat quality in broilers.

Methods: A total of 1,088 one-day-old Ross 308 broiler chicks (mixed-sex) with an initial body weight of $42.34 \pm 0.82 \mathrm{~g}$, were randomly allocated into 1 of 4 dietary treatments with 17 replicates of 16 chicks per cage and fed a basal diet supplemented with $0 \%, 0.02 \%, 0.04 \%$, and $0.06 \%$ of silymarin.

Results: The inclusion of silymarin supplementation linearly increased the body weight of broilers during days 7 to 21 and 1 to 35 days. On day 35, broilers fed a diet containing graded levels of silymarin supplementation linearly increased the nutrient digestibility of dry matter, gross energy, and nitrogen and cecal Lactobacillus counts $(\mathrm{p}=0.038)$. While silymarin supplement linearly reduced the methyl mercaptans $(p=0.039)$ and acetic acid $(p=0.007)$ emission in broilers. No significant effects were observed on the blood profile. Relative weights of organs such as breast muscle, bursa of fabricius were increased (linear effect, $\mathrm{p}<0.05$ ), water holding capacity was enhanced by increasing the silymarin level from $0 \%$ to $0.06 \%$. A linear reduction ( $p>0.05)$ in drip loss from meat samples during days $1,3,5$, and 7 by the addition of graded level of silymarin to the diet.

Conclusion: An increasing level of silymarin supplementation to the diet of broiler would be beneficial to enhance growth performance, nutrient digestibility, excreta microflora, blood profile, and meat quality traits.

Keywords: Blood Profile; Broiler; Meat Quality; Growth Performance; Silymarin

\section{INTRODUCTION}

Plants and their extracts have been used for various purposes since ancient period [1]. Besides, they are rich in phytogenics and widely used in livestock diets. For several decades, a number of feed additives including antibiotics as growth promoters (AGP) have been extensively used in livestock feedstuffs. However, the anxieties about antibiotic residues and disease resistance have aroused great caution and lead to the prohibition of the use of antibiotics in animal feed [2]. Consequently, the ban on the use of AGP as feed additives has provoked researchers to find alternative feed additives that could promote the growth performance of animals. Several researches have reported that plant extracts such as quercetin, kalongi (Nigella sativa), chicory (Cichoriumintybus), neem (Azadirachtaindica) yacon (Smallanthussonchifolius), and ginger (Zingiberofficinale) could be used as an excellent AGP $[3,4]$.

Over the past 2000 years, Silybum marianum seeds have been used as a natural drug to cure the liver and biliary duct. Silybum marianum (Milk thistle) is a native herb that is a 
member of the Carduus marianum family [4]. It grows in Northern hemisphere countries, Canada, China, Mexico, West Pakistan, and Kashmir, it has reddish-purple flowers with big leaves that are typically thorny. Dried extracts from the milk thistle seeds have approximately $60 \%$ silymarin. Silybin (flavonolignan) is the primary bioactive constituent of silymarin. Besides, it has potential antioxidant that helps to prevent lipid oxidation [5]. Furthermore, Chand et al [6] reported that Silymarin exhibits anti-inflammatory, hepatoprotective, cytoprotective, and anticarcinogenic effects. The alternation in the internal homeostasis and oxidant or antioxidant balance of broiler chickens occurs when they are exposed to some sort of stress (e.g.: immune challenges, heat stress, transport, and hatching) that leads to oxidative stress, which can have damaging effects on meat shelf life [7]. However, Tedesco et al [8] had reported the positive effects on feed utilization and consumption in broilers by the addition of silymarin. Even though many studies have reported the positive effects of silymarin in animal and human models, according to our knowledge there were few studies presented on broiler performance. Thus, we attempt this study to use silymarin as a natural growth promoter in broiler diets and evaluate how it enhances the growth performance, meat quality, excreta microbiota, nutrient retention, blood profiles and reduced gas emission.

\section{MATERIALS AND METHODS}

Prior to the trail, experimental procedures were reviewed and approved (DK-1-2032) by the Animal Care and Ethics committee of Dankook University, Cheonan, Republic of Korea.

\section{Preparation of silymarin extract}

Dried Silybum marianum seeds were pulverized and sieved through $60 \mathrm{~mm}$ - mesh size screen to produce a fine powder from which an ethyl alcohol extract (silymarin) was made. In brief, twenty grams of powder was defatted by soxhlation in three hundred milliliters of petroleum ether for sixteen hours. The defatted powder was then soaked in ethanol (300 $\mathrm{mL}$ ) for ten hours before being evaporated in a vacuum drying oven (Binder, Tuttlingen, Germany) at $39^{\circ} \mathrm{C}$.

\section{Birds' husbandry, experimental design and dietary regimen}

A total of 1,088 1-day-old (mixed-sex) Ross 308 broiler chicks with an initial average body weight (BW) of $42.34 \pm 0.82 \mathrm{~g}$ were randomly assigned to one of four experimental diets. The experimental diets were basal diet supplemented with $0 \%, 0.02 \%, 0.04 \%$, and $0.06 \%$ of silymarin. Each treatment had 17 replications with 16 birds/cage. The starter (d 1 to 7 ), grower (d 8 to 21 ), and finisher (d 22 to 35 ) diets were for- mulated according to NRC standards (Table 1) [9]. Chicks were reared in three-layer battery cages $(1.75 \mathrm{~m} \times 1.55 \mathrm{~m})$. The room temperature was kept at $33^{\circ} \mathrm{C}$ for the first 5 days, then dropped to $24^{\circ} \mathrm{C} 60$ percent humidity) until the experiment ended. Throughout the trial, the chicks had unrestricted access to water and mash feed.

\section{Sampling and clinical analysis}

Broilers were fed a nutritious diet for 35 days. At the beginning, days 7, 21, and 35 broilers were weighed on a pen basis. The amount of diet ingested, and residual (pen basis) were recorded to measure feed intake (FI). Body weight gain (BWG), FI, and feed conversion ratio (FCR) were calculated at the end of the trial, and daily mortalities (\%) were recorded, and FI data was adjusted to account for the BW of dead birds. From days 28 to 35, the feed was mixed with $0.20 \%$ chromium oxide as an indigestible marker to determine nutrient digestibility of dry matter $(\mathrm{DM})$, nitrogen $(\mathrm{N})$, and gross energy (GE). On day 35 , fresh excreta samples were grabbed (approximately $50 \mathrm{~g}$ ) from 2 cages/treatment using the stainless-steel collection tray and stored at $-20^{\circ} \mathrm{C}$. Then the samples were dried using forced convection oven for 72

Table 1. Ingredient composition of experimental diets as-fed basis

\begin{tabular}{|c|c|c|c|}
\hline Items & Starter & Grower & Finisher \\
\hline \multicolumn{4}{|l|}{ Ingredients (\%) } \\
\hline Corn & 54.19 & 55.38 & 56.77 \\
\hline Soybean meal, 45\% CP & 33.80 & 26.1 & 18.23 \\
\hline Canola meal & 5.00 & 10.0 & 15.0 \\
\hline Soybean oil & 2.10 & 3.62 & 5.07 \\
\hline MDCP & - & 1.28 & 1.12 \\
\hline DCP & 1.70 & - & - \\
\hline Limestone & 1.15 & 1.34 & 1.22 \\
\hline L-lysine, $78.4 \%$ & 0.50 & 0.65 & 0.81 \\
\hline DL-Methionine, 99\% & 0.46 & 0.47 & 0.52 \\
\hline L-Threonine, 98.5\% & 0.20 & 0.25 & 0.32 \\
\hline L-Tryptophan, 90\% & - & 0.01 & 0.04 \\
\hline $\mathrm{NaHCO}_{3}$ & 0.10 & 0.10 & 0.10 \\
\hline Salt & 0.30 & 0.30 & 0.30 \\
\hline Vitamin premix ${ }^{1)}$ & 0.20 & 0.20 & 0.20 \\
\hline Mineral premix ${ }^{2)}$ & 0.20 & 0.20 & 0.20 \\
\hline Choline & 0.10 & 0.10 & 0.10 \\
\hline \multicolumn{4}{|l|}{ Analyed values (\%) } \\
\hline Metabolizable energy (kcal/kg) & 3,000 & 3,100 & 3,200 \\
\hline Crude protein & 23.0 & 21.5 & 20.0 \\
\hline Lysine & 1.50 & 1.40 & 1.30 \\
\hline Methionine+Cystine & 1.08 & 0.99 & 0.94 \\
\hline Total phosphate & 0.48 & 0.44 & 0.41 \\
\hline Calcium & 0.96 & 0.87 & 0.81 \\
\hline \multicolumn{4}{|c|}{ 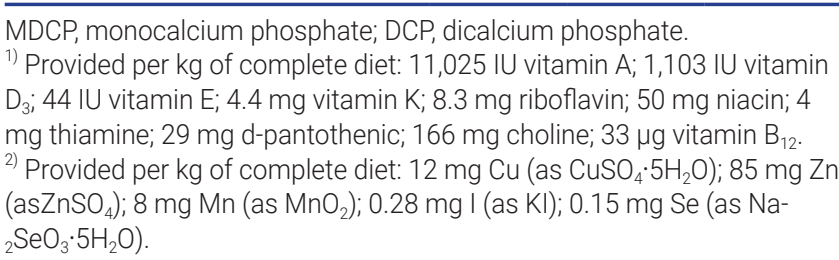 } \\
\hline
\end{tabular}


$\mathrm{h}$, pulverized, and sieved using $1 \mathrm{~mm}$ sieve. The DM analysis was done following the published method of Sampath et al [10]. The crude protein $(\mathrm{N} \times 6.25)$ absorption in the samples was determined using a Tecator Kjeltec8400 analyzer (Hoeganaes, Sweden). The GE was determined by measuring heat of combustion in the samples, using a bomb calorimeter (Parr 6100; Parr Instrument Co., Moline, IL, USA). The chromium absorption in the samples was determined using the UV1201 spectrophotometry (Shimadzu, Kyoto, Japan) and the results were recorded. Nutrient digestibility was calculated using $[1-([\mathrm{Nf} \times \mathrm{Cd}] /[\mathrm{Nd} \times \mathrm{Cf}])] \times 100$, where $\mathrm{Nf}$, nutrient concentration in excreta (\% DM); Cd, chromium concentration in diet (\% DM); Nd, nutrient concentration in diet (\% $\mathrm{DM})$; and Cf, chromium concentration in excreta (\% DM).

On day 35 , fresh excreta samples which were strewn on the stainless-steel collection tray ( 2 cages/treatment) were collected using micro-tubes, placed in sterile plastic bags, and taken to the research laboratory. To determine the presence of microorganisms, 1 gm of fresh excreta sample was diluted in $9 \mathrm{~mL}$ of $1 \%$ of peptone broth, mixed well with a vortex mixer and then $0.1 \%$ diluted samples were poured into Salmonella-Shigella, MacConkey, and Lactobacilli medium III agar plates, respectively. The Lactobacilli medium III agar plates were incubated for two days at $39^{\circ} \mathrm{C}$ whereas, Salmonella-Shigella and MacConkey agar plates were incubated for 1 day at $37^{\circ} \mathrm{C}$. Later the colonies (Lactobacillus, Escherichia coli [E. coli], Salmonella) were enumerated and $\log$ transferred for statistical analysis. On the same day, approximately $300 \mathrm{~g}$ of fresh excreta samples were collected from each treatment, pooled well, and placed in an airtight plastic box of 2,600 L with a small aperture on one side. Then the box was secured firmly with adhesive tape and fermented for 7 days at $25^{\circ} \mathrm{C}$. Following the fermentation process, the concentration of noxious gas $\left(\mathrm{NH}_{3}, \mathrm{H}_{2} \mathrm{~S}\right.$, Methyl mercaptans, $\mathrm{CO}_{2}$, and acetic acid) in the excreta sample were measured using the procedures of Nguyen and Kim [11].

At the end of the trial (d 35) blood samples were randomly drawn from the brachial veins of 34 birds/treatment using a sterile syringe and kept in (K3EDTA) (Becton, Dickinson, and Co., Franklin Lakes, NJ, USA) heparinized and nonheparinized tubes. Enzymatic kits (Roche Diagnostics GmbH, Mannheim, Germany) were used to determine low density lipoprotein (LDL)- and high-density lipoprotein (HDL)cholesterol in an automatic analyzer (Roche Cobas 6000 c501, Tokyo, Japan). An automated biochemical analyzer RA-1000 was used to assess the total cholesterol and triglyceride concentrations in blood samples (Bayer Corp., Tarrytown, NY, USA).

Following blood collection, the broilers were individually weighed, taken to the abattoir, and killed by cervical dislocation. The relative organ weight was determined by weighing each organ separately and calculating the mass BW and belly fat, liver, gizzard, spleen, breast muscle, and bursa of Fabricius were carefully removed. With a portable Konica Minolta CR-400 chroma meter (Konica Minolta, Osaka, Japan), meat color characteristics such as yellowness, redness, and brightness standards of each sample (surface) were evaluated at three places. Broiler meat $\mathrm{pH}$ was calculate using the portable $\mathrm{pH}$ suspension with two buffers ( $\mathrm{pH} 4.0$ and 7.0) and the measurement process was repeated for 2 times. For water holding capacity (WHC) 0.2 gm sample was placed in 125 $\mathrm{mm}$ (diameter) filter paper and pressed for $3 \mathrm{~min}$. The moisture-exposure of the compressed areas were determined using a digitalized area-line sensor (MT-10S; M.T. Precision Co. Ltd., Tokyo, Japan). The ratio of water: meat area was then calculated (a smaller ratio indicates increased WHC) and recorded. To estimate cooking loss, 4 gm of breast meat samples was taken, packed into zipper bags, cooked in a water bath for $20 \mathrm{~min}$ at $80^{\circ} \mathrm{C}$. Later the samples were led to cool down for $1 \mathrm{~h}$. Boiled samples were re-weighed. Finally, the cooking loss was determined by calculating the difference between the raw and boiled sample and noted. Meat samples weighing $4 \mathrm{gm}$ were sliced and weighed. Then sliced samples were placed in a Ziplock bag, stored at $4^{\circ} \mathrm{C}$, and weighed on days $1,3,5$, and 7 respectively. The initial and final weight of each sample were used to determine the drip loss level.

\section{Statistical analysis}

SAS (general linear model procedure) was used to analyze all the experimental data as a complete randomized block design (SAS Inst. Inc., Cary, NC, USA; 2000). The linear, quadratic, and cubic effects were used to investigate the polynomial contrast of increasing dietary silymarin supplementation. For growth performance, nutrient digestibility, and excreta gas emission the cage was used as an experimental unit. The individual chicken was used as the experimental unit for measuring excreta microbiota, and meat quality. Significant results were defined as less than 0.05 , while trends were defined as less than 0.10 .

\section{RESULTS}

A linear increase in BWG during days 7 to $21(\mathrm{p}=0.013)$ and overall period ( $\mathrm{p}=0.043$ ) was observed as the dietary silymarin supplementation increased from $0 \%$ to $0.06 \%$. However, there was no significant effect was observed on the FI, FCR, and mortality rate (\%) during the entire experimental period (Table 2). However, the addition of silymarin supplementation had linearly improved the nutrient digestibility of $\mathrm{DM}, \mathrm{N}$, and energy $(\mathrm{p}<0.05)$ in broilers (Table 3$)$. Also, the graded level of silymarin supplementation in broiler diet had linearly increased the Lactobacillus $(\mathrm{p}=0.038)$ population and tendency to reduce E. coli counts $(\mathrm{p}=0.075)$ (Table 4). 
Table 2. The effect of Silymarin supplementation on growth performance of broiler

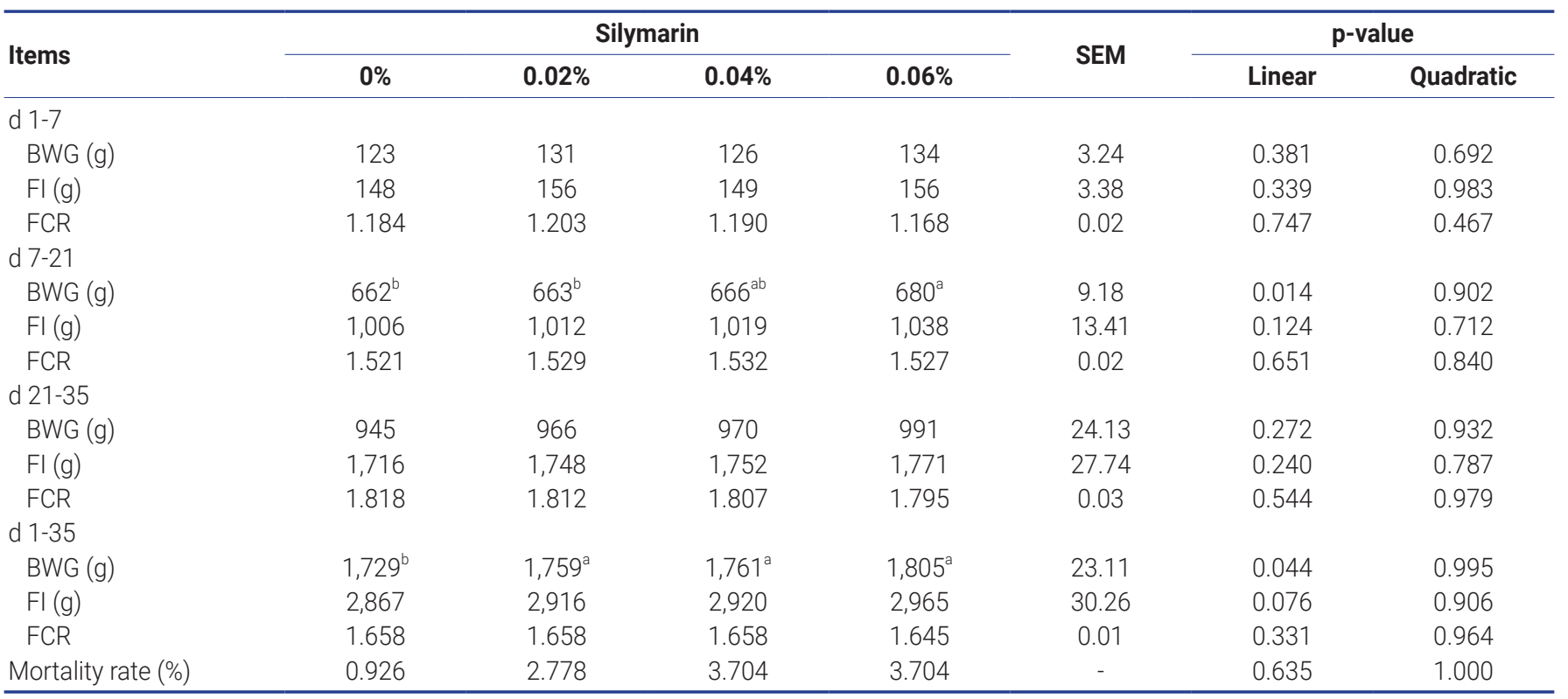

SEM, standard error of means; BWG, body weight gain; Fl, feed intake; FCR, feed conversion ratio.

a,b Means in the same row with different superscripts differ $(p<0.05)$.

Table 3. The effect of silymarin supplementation on the nutrient digestibility in broilers

\begin{tabular}{|c|c|c|c|c|c|c|c|}
\hline \multirow{2}{*}{ Items } & \multicolumn{4}{|c|}{ Silymarin } & \multirow{2}{*}{ SEM } & \multicolumn{2}{|c|}{ p-value } \\
\hline & $0 \%$ & $0.02 \%$ & $0.04 \%$ & $0.06 \%$ & & Linear & Quadratic \\
\hline \multicolumn{8}{|l|}{ d $35(\%)$} \\
\hline Nitrogen & $67.24^{\mathrm{ab}}$ & $65.75^{b}$ & $68.39^{a}$ & $68.73^{a}$ & 1.51 & $<0.001$ & 0.414 \\
\hline Energy & $73.26^{\mathrm{ab}}$ & $72.60^{b}$ & $74.40^{a}$ & $74.48^{\mathrm{a}}$ & 1.09 & 0.004 & 0.387 \\
\hline
\end{tabular}

SEM, standard error of means.

a,b Means in the same row with different superscripts differ $(p<0.05)$.

There was a linear reduction in excreta methyl mercaptans and acetic acid emission as the dietary silymarin supplementation increased from $0 \%$ to $0.06 \%$. The addition of silymarin in the diet of broilers slightly reduced $\mathrm{H}_{2} \mathrm{~S}$ emission while no differences were observed in excreta $\mathrm{CO}_{2}$ and $\mathrm{NH}_{3}$ emissions (Table 5). No treatment effects were observed on the blood profile (Table 6) of broilers fed diet containing silymarin supplementation. Though there were no statistical differences observed on meat color (lightness [L], redness [a], yellowness [b]), the relative weights of organs such as breast muscle, bursa of fabricius were linearly increased $(\mathrm{p}<0.05)$, and the spleen weight was linearly decreased with an increasing level of silymarin supplement. The inclusion of silymarin supplementation from $0 \%$ to $0.06 \%$ in the diet of broilers linearly increased $(\mathrm{p}<0.05)$ the $\mathrm{pH}$ level, WHC, and reduced the drip loss of meat from days 1, 3, 5, and 7 (Table 7).

Table 4. The effect of Silymarin supplementation on microbes in broilers

\begin{tabular}{|c|c|c|c|c|c|c|c|}
\hline \multirow{2}{*}{ Items } & \multicolumn{4}{|c|}{ Silymarin } & \multirow{2}{*}{ SEM } & \multicolumn{2}{|c|}{$\mathrm{p}$-value } \\
\hline & $0 \%$ & $0.02 \%$ & $0.04 \%$ & $0.06 \%$ & & Linear & Quadratic \\
\hline \multicolumn{8}{|l|}{ d $35\left(\log _{10} \mathrm{cfu} / \mathrm{g}\right)$} \\
\hline Lactobacillus & $7.60^{b}$ & $7.69^{\mathrm{ab}}$ & $7.87^{\mathrm{a}}$ & $7.88^{\mathrm{a}}$ & 0.19 & 0.038 & 0.361 \\
\hline Escherichia coli & 6.16 & 5.80 & 5.60 & 5.62 & 0.22 & 0.075 & 0.327 \\
\hline Salmonella & 5.23 & 4.64 & 4.55 & 4.60 & 0.29 & 0.113 & 0.232 \\
\hline
\end{tabular}

SEM, standard error of means.

a,b Means in the same row with different superscripts differ $(p<0.05)$. 
Table 5. The effect of Silymarin supplementation on the gas emission of broilers

\begin{tabular}{|c|c|c|c|c|c|c|c|}
\hline \multirow{2}{*}{ Items } & \multicolumn{4}{|c|}{ Silymarin } & \multirow{2}{*}{ SEM } & \multicolumn{2}{|c|}{ p-value } \\
\hline & $0 \%$ & $0.02 \%$ & $0.04 \%$ & $0.06 \%$ & & Linear & Quadratic \\
\hline \multicolumn{8}{|l|}{ d 35 (ppm) } \\
\hline $\mathrm{H}_{2} \mathrm{~S}$ & 1.1 & 1.3 & 1.0 & 1.1 & 0.2 & 0.068 & 0.512 \\
\hline Methyl mercaptans & $7.4^{\mathrm{a}}$ & $7.4^{\mathrm{a}}$ & $3.3^{b}$ & $4.3^{b}$ & 1.6 & 0.039 & 0.485 \\
\hline $\mathrm{CO}_{2}$ & 1,225 & 1,275 & 1,150 & 1,000 & 110 & 0.104 & 0.634 \\
\hline
\end{tabular}

SEM, standard error of means.

a,b Means in the same row with different superscripts differ $(p<0.05)$.

Table 6. The effect of Silymarin supplementation on the blood profile of broilers

\begin{tabular}{|c|c|c|c|c|c|c|c|}
\hline \multirow{2}{*}{ Items } & \multicolumn{4}{|c|}{ Silymarin } & \multirow{2}{*}{ SEM } & \multicolumn{2}{|c|}{ p-value } \\
\hline & $0 \%$ & $0.02 \%$ & $0.04 \%$ & $0.06 \%$ & & Linear & Quadratic \\
\hline \multicolumn{8}{|l|}{ d 35 (mg/dL) } \\
\hline Cholesterol & 116 & 116 & 114 & 114 & 4 & 0.229 & 0.593 \\
\hline Triglyceride & 26 & 32 & 25 & 25 & 3 & 0.086 & 0.854 \\
\hline HDL cholesterol & 83 & 83 & 86 & 86 & 4 & 0.232 & 0.651 \\
\hline LDL cholesterol & 28 & 27 & 24 & 23 & 4 & 0.054 & 0.358 \\
\hline
\end{tabular}

SEM, standard error of means; HDL, high density lipoprotein; LDL, low density lipoprotein.

\section{DISCUSSION}

The current findings showed that the dietary inclusion of silymarin supplementation improved the FI and BWG of broilers was correlated with Tedesco et al [8] who observed an increased BWG in broilers fed Silybum marianum seed supplementation. Whereas Khaleghipour et al [12] study described that increasing level silymarin supplementation reduced the FI and daily weight gain of Japanese quail fed. Previously, Blevins et al [13] reported that broilers fed a

Table 7. The effect of Silymarin supplementation on organ weight and meat quality in broilers

\begin{tabular}{|c|c|c|c|c|c|c|c|}
\hline \multirow{2}{*}{ Items } & \multicolumn{4}{|c|}{ Silymarin } & \multirow{2}{*}{ SEM } & \multicolumn{2}{|c|}{ p-value } \\
\hline & $0 \%$ & $0.02 \%$ & $0.04 \%$ & $0.06 \%$ & & Linear & Quadratic \\
\hline \multicolumn{8}{|l|}{ d 35} \\
\hline \multicolumn{8}{|c|}{ Relative organ weight (\%) } \\
\hline Breast muscle & $18.86^{\mathrm{b}}$ & $19.39^{b}$ & $19.41^{\mathrm{a}}$ & $19.63^{\mathrm{a}}$ & 0.52 & 0.023 & 0.191 \\
\hline Liver & 2.55 & 2.47 & 2.39 & 2.40 & 0.10 & 0.132 & 0.473 \\
\hline Spleen & $0.14^{a}$ & $0.14^{a}$ & $0.13^{b}$ & $0.13^{b}$ & 0.01 & 0.001 & 0.051 \\
\hline Abdominal fat & 1.12 & 1.10 & 0.82 & 0.81 & 0.14 & 0.084 & 0.854 \\
\hline Bursa of Fabricius & 0.17 & 0.16 & 0.16 & 0.18 & 0.10 & 0.047 & 0.315 \\
\hline Gizzard & 1.32 & 1.35 & 1.23 & 1.28 & 0.02 & 0.122 & 0.325 \\
\hline \multicolumn{8}{|l|}{ Breast muscle color } \\
\hline Lightness $\left(L^{*}\right)$ & 52.00 & 54.85 & 52.01 & 53.14 & 1.16 & 0.473 & 0.226 \\
\hline Redness $\left(a^{*}\right)$ & 12.89 & 14.43 & 14.26 & 14.58 & 0.69 & 0.334 & 0.715 \\
\hline Yellowness (b*) & 12.36 & 15.60 & 14.45 & 14.01 & 1.01 & 0.592 & 0.072 \\
\hline $\mathrm{pH}$ value & $5.51^{b}$ & $5.50^{\mathrm{ab}}$ & $5.62^{\mathrm{ab}}$ & $5.85^{\mathrm{a}}$ & 0.10 & 0.012 & 0.439 \\
\hline Cooking loss (\%) & 28.09 & 28.73 & 30.98 & 28.97 & 1.52 & 0.505 & 0.759 \\
\hline WHC (\%) & 53.62 & 49.45 & 54.30 & 55.20 & 2.43 & 0.018 & 0.788 \\
\hline \multicolumn{8}{|l|}{ Drip loss (\%) } \\
\hline Day 1 & $1.72^{\mathrm{a}}$ & $2.24^{a}$ & $1.68^{b}$ & $1.64^{b}$ & 0.22 & 0.001 & 0.863 \\
\hline Day 3 & $3.71^{\mathrm{ab}}$ & $4.01^{a}$ & $3.60^{b}$ & $3.65^{b}$ & 0.29 & 0.001 & 0.605 \\
\hline Day 5 & $6.00^{\mathrm{a}}$ & $5.73^{\mathrm{a}}$ & $5.64^{b}$ & $5.66^{b}$ & 0.25 & 0.033 & 0.154 \\
\hline Day 7 & $7.42^{\mathrm{a}}$ & $7.52^{\mathrm{a}}$ & $7.20^{\mathrm{b}}$ & $7.18^{b}$ & 0.30 & 0.007 & 0.718 \\
\hline
\end{tabular}

SEM, standard error of means; WHC, water holding capacity.

${ }^{a, b}$ Means in the same row with different superscripts differ $(p<0.05)$. 
diet containing Silybum marianum showed no improvements in their feed efficacy. Likewise, Schiavone et al [14] reported that the addition of silymarin supplementation in broilers diet had no positive effects on their growth performance. Jang et al [15] demonstrated that broilers fed diets containing a high dose of plant extract mixtures (carvacrol, cinnamaldehyde, and capsaicin) showed significantly increased activities of pancreatic trypsin and a-amylase, as well as intestinal maltase, compared with the birds fed control and antibiotic diets. We assume that the probable reason for increased weight gain of the broilers might be due to the presence of growth enhancing properties in silymarin extract. In addition, it is possible to alter the digestibility by changing intestinal microflora. The plant extract gives beneficial microorganisms an advantage in nutrient competition with harmful microorganisms by limiting the growth of harmful microorganisms in the intestines, which can increase the nutrient digestibility of broiler chickens [16]. The number of species, herbs, and plant extracts has been reported to enhance digestibility function by stimulating the secretion of digestive enzymes in the gastric mucosa and increasing nutrient intake in broiler [17]. For instance: Jang et al [15] found that broilers fed a diet rich in plant combinations such as cinnamaldehyde, capsaicin, and carvacrol had considerably higher pancreatic trypsin and -amylase activity, as well as intestinal maltase activity, than control and antibiotic-fed chickens. In this study, the nutrient digestibility of DM, nitrogen, and GE had linearly increased in broilers fed silymarin supplemented diets.

The species and populations of microorganisms in the digestive system have a great impact on gut health [18]. Zhu et al [19] demonstrated that chicken's digestive tract is not only complicated, but it also contains live microbial communities that could play an important role in promoting their intestinal health. Lactobacillus are beneficial intestinal bacteria, whereas, E. coli and Salmonella bacteria frequently cause gut health issues in young animals. The dietary silymarin supplementation $500 \mathrm{ppm}$ and $1,000 \mathrm{ppm}$ resulted in reduced bacterial counts at both days 28 and 42 in aflatoxin-challenged broiler chicks [20]. As we all know, an increased in Lactobacillus and decreased E. coli count in broilers results in better intestinal health [21]. In this study, lactic acid bacteria (Lactobacillus) were linearly increased, and coliform bacteria (E. coli) showed a tendency in reduction by increasing the level of silymarin concentration in the diet. The decreased coliform bacteria count and increased lactic acid bacteria counts may also serve as further evidence to explain the improved broiler weight gain and nutrient digestibility. The most hazardous gases in poultry are ammonia, methane, hydrogen sulfide, and carbon dioxide [22]. The environment, animals' health, and production are affected by odor emissions from livestock industries and lead to civil complaints
[16]. The fecal noxious gas content in pigs was decreased when herbal extract mixture supplementation was included [23]. In our study, methyl mercaptans and acetic acid were significantly reduced. Sharma et al [24] found that supplementing the diet with plant extracts or phytogenic feed additives including saponin and polyphenol reduced volatile chemicals in broiler excreta ammonia gas emission. However, there were no significant differences found in $\mathrm{CO}_{2}$ and $\mathrm{NH}_{3}$ emission. The inconsistent results regarding excreta noxious gas emission may be due to the difference in dosage levels or animals. The findings on silymarin extract reducing the excreta gas emissions in broiler chickens are limited thus sufficient comparison could not be made.

Metwally et al [25] demonstrated that addition of a silymarin concentrate produced significant decrease the triglyceride, HDL, LDL cholesterol concentrations in rats. However, in the present study, triglyceride, HDL, and LDL cholesterol concentration showed no treatment effects by the inclusion of graded level of Silymarin in the diet. In addition, Banaee et al [26] stated that the activity of silymarin in fish decreases plasma glucose and total cholesterol levels almost completely. Tumova et al [27] noted that the inclusion of silymarin decreases serum cholesterol levels and HDL levels which were slightly higher. In the in vitro culture technology using silybin it was found that the intake of 3 hydroxy 3- methylglutaryl co enzyme A reductase, which is an important enzyme in cholesterol synthesis [28] has a possible direct influence on liver cholesterol metabolism. Moreover, Silymarin is related to the decrease in liver cholesterol [29] and this function is mainly due to fat-mediated improved bioavailability and/ or by inhibition of resorption of dietary cholesterol. And the birds which were treated with silymarin had reduced concentrations of triglycerides which is in line with Khazaei et al [30] who observed a similar result in Japanese quail. Recently, consumers are very much concerned about the safety and quality of meat. Therefore, it is important to assess meat quality [31]. Hossain et al [32] stated that the $\mathrm{pH}$ of meat is directly related to the quality of muscle acid and has an impact on the sheer intensity, drip loss, and color of meat. The present results showed that a significant effect on the $\mathrm{pH}$ value, drip loss, and WHC. There is lack of information on the effect silymarin on meat quality, including WHC and natural drip loss in broiler chicken. An important effect that takes place in meat quality is drip loss. Reis et al [33] stated that a higher level of WHC of meat broiler chickens is mainly due to the feed additives which depend on essential oils. Nutrient elevation takes place by water loss which mainly leads to loss of juiciness, tenderness of meat [34]. Balamuralikrishnan et al [35] stated that drip loss was an ordinary indicator and lesser drip loss indicates better meat quality. Previously, Duclos et al [36] reported that the carcass with a higher level of meat yield and with 
lesser fat indicated a better meat quality. Likewise, Fani Makki et al [37] reported that Silybum marianum seed had a significant effect on bursa, spleen, abdominal fat, liver, and gizzard and these results agreed with our study, in which broilers fed $0.06 \%$ silymarin supplementation had significantly increased breast meat yields, bursa of fabricius and reduced abdominal fats, and spleen. Due to the lack of literature on the effect of silymarin on the meat quality of broilers further comparisons cannot be made.

\section{CONCLUSION}

Based on the current findings, it can be concluded that increasing levels of silymarin supplementation up to $0.06 \%$ to the diet of broilers would be beneficial in improving the growth performance, nutrient digestibility, excreta microflora, blood profile, and meat quality traits.

\section{CONFLICT OF INTEREST}

We certify that there is no conflict of interest with any financial organization regarding the material discussed in the manuscript.

\section{FUNDING}

The authors received no financial support for this article.

\section{REFERENCES}

1. Kuralkar P, Kuralkar SV. Role of herbal products in animal production - an updated review. J Ethnopharmacol 2021; 278:114246. https://doi.org/10.1016/j.jep.2021.114246

2. Sureshkumar S, Sampath V, Kim IH. The influence of dietary inclusion of wood vinegar supplementation on growth performance, nutrient digestibility, and meat quality in growerfinisher pigs. Acta Biochimica Polonica 2021;68:287-92. https:// doi.org/10.18388/abp.2020_5564

3. Dhama K, Latheef SK, Mani S, et al. Multiple beneficial applications and modes of action of herbs in poultry health and production. A review. Int J Pharmacol 2015;11:152-76. https://doi.org/10.3923/ijp.2015.152.176

4. Saeed M, Babazadeh D, Arif M, et al. Silymarin: a potent hepatoprotective agent in poultry industry. Worlds Poult Sci J 2017;73:483-92. https://doi.org/10.1017/S0043933917 000538

5. Madrigal-Santillán E, Madrigal-Bujaidar E, Álvarez-González I, et al. Review of natural products with hepatoprotective effects. World J Gastroenterol 2014;20:14787-804. https:// doi.org/10.3748/wjg.v20.i40.14787

6. Chand N, Din M, Durrani FR, Qureshi MS, Ullah SS. Protective effects of milk thistle (Silybum marianum) against aflatoxin B1 in broiler chicks. Asian-Australas J Anim Sci 2011;24:1011-8. https://doi.org/10.5713/ajas.2011.10418

7. Young JF, Stagsted J, Jensen SK, Karlsson AH, Henckel P. Ascorbic acid, alpha-tocopherol, and oregano supplements reduce stress-induced deterioration of chicken meat quality. Poult Sci 2003;82:1343-51. https://doi.org/10.1093/ps/82.8. 1343

8. Tedesco D, Steidler S, Galletti S, Tameni M, Sonzogni O, Ravarotto L. Efficacy of silymarin-phospholipid complex in reducing the toxicity of aflatoxin B1 in broiler chicks. Poult Sci 2004;83:1839-43.

9. NRC (National Research Council). Nutrient requirements of poultry. 9th rev. ed. Washington, DC, USA: National Academies Press; 1994.

10.Sampath V, Shanmugam S, Park JH, Kim IH. The effect of black pepper (Piperine) extract supplementation on growth performance, nutrient digestibility, fecal microbial, fecal gas emission, and meat quality of finishing pigs. Animals 2020; 10:1965. https://doi.org/10.3390/ani10111965

11. Nguyen DH, Kim IH. Protected organic acids improved growth performance, nutrient digestibility, and decreased gas emission in broilers. Animals 2020;10:416. https://doi. org/10.3390/ani10030416

12. Khaleghipour B, Khosravinia H, Toghiyani M, Azarfar A. Effects of silymarin on productive performance, liver function and serum biochemical profile in broiler Japanese quail challenged with dietary aflatoxins. Ital J Anim Sci 2019;18:56473. https://doi.org/10.1080/1828051X.2018.1548310

13. Blevins S, Siegel PB, Blodgett DJ, Ehrich M, Saunders GK, Lewis RM. Effects of silymarin on gossypol toxicosis in divergent lines of chickens. Poult Sci 2010;89:1878-86. https://doi. org/10.3382/ps.2010-00768

14.Schiavone A, Righi F, Quarantelli A, Bruni R, Serventi P, Fusari A. Use of Silybum marianum fruit extract in broiler chicken nutrition: influence on performance and meat quality. J Anim Physiol Anim Nutr 2007;91:256-62. https://doi.org/ 10.1111/j. 1439-0396.2007.00701.x

15.Jang IS, Ko YH, Kang SY, Lee CY. Effect of a commercial essential oil on growth performance, digestive enzyme activity and intestinal microflora population in broiler chickens. Anim Feed Sci Technol 2007;134:304-15. https://doi.org/10. 1016/j.anifeedsci.2006.06.009

16. Park JH, Kim IH. Effects of dietary Achyranthes japonica extract supplementation on the growth performance, total tract digestibility, cecal microflora, excreta noxious gas emission, and meat quality of broiler chickens. Poult Sci 2020;99:46370. https://doi.org/10.3382/ps/pez533

17.Srinivasan K. Spices as influencers of body metabolism: an overview of three decades of research. Food Res Int 2005;38: 77-86. https://doi.org/10.1016/j.foodres.2004.09.001

18. Yang Y, Kiarie E, Slominski BA, Brûlé-Babel A, Nyachoti CM. Amino acid and fiber digestibility, intestinal bacterial 
profile, and enzyme activity in growing pigs fed dried distillers grains with solubles-based diets. J Anim Sci 2010;88:330412. https://doi.org/10.2527/jas.2009-2318

19.Zhu XY, Zhong T, Pandya Y, Joerger RD. 16S rRNA-based analysis of microbiota from the cecum of broiler chickens. Appl Environ Microbiol 2002;68:124-37. https://doi.org/10. 1128/AEM.68.1.124-137.2002

20.Jahanian E, Mahdavi AH, Asgary S, Jahanian R. Effects of dietary inclusion of silymarin on performance, intestinal morphology and ileal bacterial count in aflatoxin-challenged broiler chicks. J Anim Physiol Anim Nutr 2017;101:e43e54. https://doi.org/10.1111/jpn.12556

21.Jin LZ, Ho YW, Abdullah N, Jalaludin S. Digestive and bacterial enzyme activities in broilers fed diets supplemented with Lactobacillus cultures. Poult Sci 2000;79:886-91. https://doi. org/10.1093/ps/79.6.886

22.Gates RS, Casey KD, Wheeler EF, Xin H, Pescatore AJ. U.S. broiler housing ammonia emissions inventory. Atmos Environ 2008;42:3342-50. https://doi.org/10.1016/j.atmosenv.2007. 06.057

23. Yan L, Meng QW, Kim IH. The effect of an herb extract mixture on growth performance, nutrient digestibility, blood characteristics and fecal noxious gas content in growing pigs. Livest Sci 2011;141:143-7. https://doi.org/10.1016/j.livsci.2011.05. 011

24. Sharma NK, Choct M, Dunlop MW, Wu SB, Castada HZ, Swick RA. Characterisation and quantification of changes in odorants from litter headspace of meat chickens fed diets varying in protein levels and additives. Poult Sci 2017;96: 851-60. https://doi.org/10.3382/ps/pew309

25.Metwally MAA, El-Gellal AM, El-Sawaisi SM. Effects of silymarin on lipid metabolism in rats. World Appl Sci J 2009; 6:1634-7.

26. Banaee M, Sureda A, Mirvaghefi AR, Rafei GR. Effects of long-term silymarin oral supplementation on the blood biochemical profile of rainbow trout (Oncorhynchus mykiss). Fish Physiol Biochem 2011;37:885-96. https://doi.org/10. 1007/s10695-011-9486-Z

27.Tumova L, Tuma J, Megusar K, Dolezal M. Substituted pyrazinecarboxamides as abiotic elicitors of flavolignan production in Silybum marianum (L.) gaertn cultures in vitro. Molecules 2010;15:331-40. https://doi.org/10.3390/ molecules 15010331
28. Nassuato G, Iemmolo RM, Strazzabosco M, et al. Effect of Silibinin on biliary lipid composition experimental and clinical study. J Hepatol 1991;12:290-5. https://doi.org/10.1016/01688278(91)90829-Z

29. Krecman V, Skottova N, Walterova D, Ulrichova J, Simanek V. Silymarin inhibits the development of diet-induced hypercholesterolemia in rats. Planta Med 1998;64:138-42. https:// doi.org/10.1055/s-2006-957391

30. Khazaei R, Seidavi A, Bouyeh M. A review on the mechanisms of the effect of silymarin in milk thistle (Silybum marianum) on some laboratory animals. Vet Med Sci 2022;8:289-301. https://doi.org/10.1002/vms3.641

31.Ishamri I, Joo1 ST. Poultry meat quality in relation to muscle growth and muscle fiber characteristics. Korean J Food Sci Anim Resour 2017;37:873-83.

32. Hossain MM, Begum M, Kim IH. Effect of Bacillus subtilis, Clostridium butyricum and Lactobacillus acidophilus endospores on growth performance, nutrient digestibility, meat quality, relative organ weight, microbial shedding and excreta noxious gas emission in broilers. Vet Med 2015;60:77-86. https://doi.org/10.17221/7981-VETMED

33. Reis JH, Gebert RR, Barreta M, et al. Effects of phytogenic feed additive based on thymol, carvacrol and cinnamic aldehyde on body weight, blood parameters and environmental bacteria in broilers chickens. Microb Pathog 2018; 125:168-76. https://doi.org/10.1016/j.micpath.2018.09.015

34. Chen H, Dong X, Yao Z, et al. Effects of prechilling parameters on water-holding capacity of chilled pork and optimization af prechilling parameters using response surface methodology. J Anim Sci 2012;90:2836-41. https://doi.org/10.2527/jas.20114239

35. Balamuralikrishnan B, Sang IL, Kim IH. Inclusion of dietary multi-species probiotic on growth performance, nutrient digestibility, meat quality traits, faecal microbiota and diarrhoea score in growing-finishing pigs. Ital J Anim Sci 2018;17:1006. https://doi.org/10.1080/1828051X.2017.1340097

36. Duclos MJ, Berri C, Le Bihan-Duval E. Muscle growth and meat quality. J Appl Poult Res 2007;16:107-12. https://doi. org/10.1093/japr/16.1.107

37. Fani Makki O, Afzali N, Omidi A. Effect of different levels of Silymarin (Silybum marianum) on growth rate, carcass variables and liver morphology of broiler chickens contaminated with aflatoxin B1. Poult Sci J 2013;1:105-16. 